\title{
ANALYSING THE MACRO- ORGANISATIONAL STRUCTURE OF THE REVIEW ARTICLE GENRE IN APPLIED LINGUISTICS
}

\author{
Ali Sorayyaei AZAR \\ Azirah HASHIM ${ }^{2}$ \\ Department of English Language, Faculty of Languages and Linguistics, \\ University of Malaya, 50603 Kuala Lumpur, Malaysia. \\ ${ }^{1}$ asorayaie@siswa.um.edu.my* \\ 2 azirahh@um.edu.my
}

*Corresponding author

Manuscript received 17 April 2017

Manuscript accepted 19 June 2017

\begin{abstract}
The aim of this research is (1) to analyse the macro-organisational structure and (2) to investigate and describe the analytical sections of the data. The data, drawn from a randomly selected corpus of 32 review articles, was analysed following Swales' (1990) genre analysis to describe and investigate the schematic structure of the review article genre. The findings revealed that the CARS model was often observed in this genre. Moreover, although both review articles and research articles have been considered sub-genres of the research genre, there is a significant variation among them in terms of the schematic structure, rhetorical strategies, and functions. The schematic structure and functions of the review article genre were further investigated by consulting the specialist informants. The macroorganisational structure of this genre proposed hence provide the instructive guidance for EFL graduates and junior researchers how to review the developments critically during their research writing.
\end{abstract}

Keywords: academic review genres, review article genre, macro-organisational structure, analytical sections of review article genre

\section{Introduction}

During four decades, genre analysis is still a valuable and productive method for analysing the schematic structure of academic discourses. Many researchers have adopted Swales' (1990) CARS model to analyse Moves and Steps of academic texts. They have followed English for Specific Purposes (ESP) approach to identify the 
functions of the academic texts. The functions and communicative purposes of the academic discourses have been represented with a set of moves and steps. It was noticed that these structures cannot be in a fixed order or sequence. In addition, they are changing over time. By doing genre analysis, the researchers are able to suggest organisational structures and schematic patterns for the academic texts in their disciplines.

For this reason, one perspective of genre analysis is to focus on academic discourses and their analytical sections (i.e. the Introduction, Review of literature, Methodology, Results and Discussion, and Conclusion sections). In addition, academic review genres have been studied extensively over the last decade, in particular the book reviews (Groom, 2009; Hyland \& Diani, 2009; Moreno \& Suarez, 2008; Motta-Roth, 1995), literature review sections in PhD theses (Kwan, 2006; Ridley, 2008; Thompson, 2009), and review articles (Myer, 1991; Noguchi, 2006; Sorayyaei Azar \& Hashim, 2014, 2017a, 2017b; Swales, 2004). However, academic review genres still require much more analysis especially review articles. Until recently, there have been many studies focusing on the macro-organisational structure of research article sections and other academic discourses, but very few studies have focused on the schematic structure of review article genre. Among the various types of academic review genre, the review article genre has attracted the most attention due to its significant purposes and classification. It also plays an important rhetorical role in creating a research gap, raising a research problem, and evaluating the works and establishing "praise and criticism interactions" of authors (Hyland, 2000).

The valuable knowledge about the generic structure of academic review genres is needed for EFL postgraduate students and junior researchers so that they can strategically develop their comprehensive research and review the developments of a research in the related field critically. These types of studies are useful for teachers and postgraduate students. The contribution of these studies to the teaching field is valuable and the knowledge genre analysis is applicable.

In fact, the genre-based studies focus basically on introducing Moves and Sub-moves (i.e. Steps or Strategies) of academic discourses. They not only generate sets of Moves and Sub-moves, but they also analyse linguistic features of the texts. We can emphasise that one can acquire genre knowledge by focusing on learning the typical macro-structure and schematic knowledge of academic discourses. Hence, dealing with the schematic structure needs to be situated with our learners' and novice writers' ethnographic awareness. Due to this need, we analysed the macro-organisational structure of review articles in Applied Linguistics ${ }^{1}$. Besides, we described and analysed the analytical sections of review articles (i.e. the Abstract, Introduction, Body and Conclusion sections). The ethnographic accounts were also collected and used to confirm and back up the findings of this genre-based study. Swales' (1990) CARS structure was observed to some extent in the review article genre. Moreover, the IMRD model is an adequate model for experimental research papers, this model has been rarely observed in the review article genre, except in a few cases. Thus, we have suggested the rhetorical model of the review article genre in Applied Linguistics which is different from the IMRD structure. 


\section{The Research Questions}

This study aims at giving answers to the following questions:

1. What is the macro-organisational structure of the review article genre in applied linguistics?

2. What are the schematic structures of the analytical sections of the review article genre in applied linguistics?

3. Do the schematic structures of the analytical sections in review articles follow the CARS model?

\section{A Brief Review of Related Literature}

The review article genre has been generally understood as a brief survey of relevant literature and this type of review genre has been in circulation since the $18^{\text {th }}$ century (Kronick, 1976, as cited in Garfield, 1987a, p. 113). On the contrary, review article texts can be characterised by two major types as stated by Adams (1961), namely, (1) discipline review and (2) categorical review. These were two types which belonged to the 19th century German review types. The former is a comprehensive description record, while the latter is a highly selective and critical one and it focuses on a problem and presents its solution. In another view, Woodward (1974) believed that there can be eight types of reviews, namely, critical, evaluation, interpretive, speculative, state of the art, tutorial, historical and popular. Thus, it can be contended that it is not normally a brief survey of relevant literature. For instance, if a review is a critical one it can focus on critical evaluation of published information and ideas. To be short, the review article is a valuable source, as it has been suggested, not only for being an integrative and a synthesised-form scientific article but also for being a source for data access (Garfield, 1987). As Price (1965) suggested, after publishing thirty or forty research articles in any field we will need a review. In fact, we can conclude that it is often difficult to give a single definition of a review article because as mentioned above the review article in any discipline and its related fields may take various forms and functions.

With the given definitions and characterisations in mind, there can be more than one function for the review article, namely, (1) historical function and (2) contemporary function (Woodward, 1977). It seems that the categorical review article mostly often likes to perform the historical function, while the bibliographic review article which provides merely a survey of the current literature tends to perform the contemporary function (Woodward, 1977, p. 176). Although there was common agreement that reviews fulfill two primary functions, we can certainly find out from findings of other studies this double role of the reviews obviously needs to be called into question. In publishing reviews, there might be significant factors affecting their characteristic features, categorisation and functions. Review writers are sought out by editors and solicited to write on a given subject field. The editorial policy, the exact scope and overall format of the journal, the discipline itself, and author's communicative purpose lead to the variation of the reviews. For example, Noguchi $(2001,2006)$ classified the science review article genre into four main categories: (1) history, (2) status quo, (3) theory, and (4) issue. As Swales (2004) 
pointed out there are no discoursal studies of review articles discussed at length in writing manuals except two: Myers (1991) and Noguchi (2001). Myers examined review articles of two prominent molecular biologists. It is stated that a review article draws readers into the writer's views of what has happened and by ordering the recent past, it suggests what can be done next (Myers, 1991, p. 46). Neglected review genre, as Noguchi (2001) stated in her doctoral dissertation, offers a publishing opportunity, because review articles are more flexible and less frozen than the standard research articles. She applied textual analysis and the informants' views to 25 science review articles. Moreover, she suggested review article is a different genre and it is going to become increasingly important. The review article genre, thus, plays a significant role for those people in creating knowledge and informing them on how to manage their own learning and how to make use of scholarly reviews. Given the scant attention to the review article genre in the field of applied linguistics, the present study is important.

\section{The Study}

The corpus used for this study comprised 32 review articles in the field of applied linguistics, each 18-20 pages on average, published in an established journal between 2000 to 2007 entitled: Annual Review of Applied Linguistics (ARAL published by Cambridge University Press). The prestige and reputation of this journal in publishing review articles were taken into account. Yet, another criterion involved in sampling procedure of this study was to consult the specialist informants in that field, this is known as "informant nomination" the established tradition in sampling and targeting the corpus-based studies (Hyland, 2000, 2007; Kuhi \& Behnam, 2010; Kuhi, Yavari, \& Sorayyaei Azar, 2012). They were asked to name the most prestigious journals in which their review articles were published and the corpus were selected from these (see Appendix A).

The first step was to identify the prevalent analytical sections of the corpus. By concentrating on the organisational structure and textual devices of these sections of the corpus, we attempted to investigate the purposes and characteristic features of the prevalent sections of review articles in applied linguistics. Such an analysis of the textual/ or organisational structure of the review article genre is a necessary prerequisite to the investigation of this type of genre. In this study, two sets of clues were used to investigate the purposes and the schematic structure of this review genre: Moves (see Appendix B for the examples of moves provided from the corpus to illustrate the move structures) and the specialist informants' feedback. The specialist informants used for this research were in fact the authors of the review articles (in ARAL).

In the second step, we referred to the specialist informants through emailing interview and personal communication. It is essential to look inside the academic discourse community in order to learn about the discourse structure, categorisation and classification system, and functions of the review article genre. For this reason, several semi-structured questions related to the informants' review articles were posed. These questions were in terms of their main aim of writing and publishing this type of academic review genre in ARAL journal and also clarifying the 
classification system, functions, and the generic structure of review articles. Tables 1 and 2 provide the two frameworks taken from Hatim and Mason (1990) and Yang and Allison (2003).

Table 1

Hatim and Mason's framework (1990)

\begin{tabular}{ll}
\hline \multicolumn{1}{c}{ Through-argumentation } & \multicolumn{1}{c}{ Counter-argumentation } \\
\hline i. Thesis to be supported & i. Thesis cited to be opposed \\
$\begin{array}{l}\text { ii. Substantiation } \\
\text { iii. Conclusion }\end{array}$ & ii. Opposition/ Counter-claim/ \\
& iii. Substantiation of counter-claim \\
& iv. Conclusion \\
\hline
\end{tabular}

Table 2

Yang and Allison's framework (2003)

\begin{tabular}{cc}
\hline Moves & \multicolumn{1}{c}{ Steps } \\
\hline 1 & Summarising the study \\
2 & Evaluating the study \\
& i. $\quad$ Indicating significance/advantage \\
& ii. Indicating limitations \\
& iii. Evaluating methodology \\
3 & Deductions from the research \\
& i. $\quad$ Recommending further study \\
& ii. $\quad$ Drawing pedagogic implication \\
\hline
\end{tabular}

\section{Macro-organisational Structure of the Review Article Genre in Applied Linguistics}

The main focus of the present research is on the macro-organisational structure of review articles in applied linguistics. There is a variation with respect to the organisational structure that exists within the review article genre and it differs from experimental research article, systematic reviews, book reviews, and book review articles. According to Swales (1990) and Weissburg and Buker's (1990) presentation, the different sections of the experimental research articles follow the IMRD model. In contrast with the sections of the experimental research article, the present study shows that there are four main predominant sections in the corpus of the present research (Table 3). The prevalent sections for review articles include the Abstract section (87.5\%), the Introduction section (90\%), theme-bound units (consists of content-based headings and sub-headings) in the Body section (100\%), and the Conclusion section or Concluding Remarks (87.5\%). Apart from that, there are three main types of review articles in the corpus of this research which are: (1) the bibliographic review article which gives readers a comprehensive and descriptive record of annual works and it encompasses the literature-oriented approach, (2) the critical evaluative review article which encompasses subject-oriented approach, that is to say it identifies an idea or raises a research problem, then it gives its solution by analysing and evaluating the selective works done before in the related field, and finally it suggests a new direction, and (3) the mixed-mode review article which has the twin roles and encompasses both literature-oriented and subject-oriented 
approaches (see Sorayyaei Azar \& Hashim 2014). The $47 \%$ of review articles in this research involve mixed-mode reviews (15 out of 32 ) and the rest of the reviews belongs to both classes, that is to say, the rate of distribution for the two classes is: $28 \%$ of the reviews involve critical evaluative reviews (9 out of 32 ) and $25 \%$ of the reviews involve bibliographic reviews (8 out of 32 ).

Table 3

Frequency of prevalent sections in review articles

\begin{tabular}{ccc}
\hline Sections & Frequency & Percentage (\%) \\
\hline Abstract & $28 / 32$ & $87.5 \%$ \\
Introduction & $29 / 32$ & $90 \%$ \\
The Body & $32 / 32$ & $100 \%$ \\
Conclusion & $28 / 32$ & $87.5 \%$ \\
\hline
\end{tabular}

Based on the analysis of overall organisational structure of review articles, the following specific details were provided for each one of the review article genre. Table 4 displays the specific features of each review article in the corpus. They include the number of authors per text, average self-citation and average number of pages for each text, the type of section headings provided and if the four sections of the review article texts exist.

Table 4

Specific features of review articles in this research

\begin{tabular}{|c|c|c|c|c|c|c|c|c|c|c|}
\hline $\begin{array}{l}\text { Data } \\
\text { No. }\end{array}$ & $\begin{array}{l}\text { Sin- } \\
\text { gled } \\
\text { Au- } \\
\text { thor }\end{array}$ & $\begin{array}{l}\text { Date } \\
\text { of } \\
\text { Pub. }\end{array}$ & Abs. & $\begin{array}{l}\text { In- } \\
\text { tro }\end{array}$ & $\begin{array}{l}\text { The } \\
\text { Main } \\
\text { Body }\end{array}$ & Conc & $\begin{array}{l}\text { Avera } \\
\text {-ge } \\
\text { no. } \\
\text { Refe- } \\
\text { rence } \\
\text { s }\end{array}$ & $\begin{array}{l}\text { Aver- } \\
\text { age } \\
\text { Self- } \\
\text { Cita- } \\
\text { tion }\end{array}$ & $\begin{array}{l}\text { Ta- } \\
\text { bles, } \\
\text { Cha- } \\
\text { rts, } \\
\text { Fi- } \\
\text { gures }\end{array}$ & $\begin{array}{l}\text { Ave- } \\
\text { rage } \\
\text { no. } \\
\text { of } \mathrm{Pa}- \\
\text { ges }\end{array}$ \\
\hline RevA.1 & Yes & 2000 & NO & * & $* * *$ & NO & 15 & 3 & - & 12 \\
\hline RevA.2 & Yes & 2000 & NO & $*$ & $* * *$ & $* * *$ & $\begin{array}{l}\text { A.14+ } \\
92\end{array}$ & 5 & - & 21 \\
\hline RevA.3 & Yes & 2000 & NO & NO & $* * *$ & $* * *$ & $\begin{array}{l}\text { A.17+ } \\
63\end{array}$ & 3 & - & 17 \\
\hline RevA.4 & Yes & 2000 & NO & $*$ & $* * *$ & $*$ & $\begin{array}{l}\text { A. } 3+7 \\
9\end{array}$ & 12 & - & 19 \\
\hline RevA.5 & Yes & 2001 & $* *$ & $* *$ & $* * *$ & $*$ & $\begin{array}{l}\text { A. } 4+8 \\
1\end{array}$ & 3 & - & 19 \\
\hline RevA.6 & Yes & 2001 & $* *$ & $* \mathrm{E}$ & $* * *$ & $*$ & $\begin{array}{l}\text { A.6+4 } \\
5\end{array}$ & 2 & Fig.1 & 19 \\
\hline RevA.7 & Yes & 2001 & $* *$ & $* *$ & $* * *$ & $*$ & $\begin{array}{l}\text { A. } 6+7 \\
9\end{array}$ & 13 & - & 16 \\
\hline RevA.8 & Yes & 2001 & $* *$ & $* *$ & $* * *$ & $*$ & $\begin{array}{l}\text { A. } 3+5 \\
9\end{array}$ & 11 & T.1 & 13 \\
\hline RevA.9 & NO & 2002 & $* *$ & $* *$ & $* * *$ & $*$ & 204 & 38 & - & 28 \\
\hline
\end{tabular}


Table 4 (continued).

\begin{tabular}{|c|c|c|c|c|c|c|c|c|c|c|}
\hline $\begin{array}{l}\text { Data } \\
\text { No. }\end{array}$ & $\begin{array}{l}\text { Sin- } \\
\text { gled } \\
\text { Au- } \\
\text { thor }\end{array}$ & $\begin{array}{l}\text { Date } \\
\text { of } \\
\text { Pub. }\end{array}$ & Abs. & $\begin{array}{l}\text { In- } \\
\text { tro }\end{array}$ & $\begin{array}{l}\text { The } \\
\text { Main } \\
\text { Body }\end{array}$ & Conc & $\begin{array}{l}\text { Avera } \\
\text {-ge } \\
\text { no. } \\
\text { Refe- } \\
\text { rence } \\
\text { s } \\
\end{array}$ & $\begin{array}{l}\text { Aver- } \\
\text { age } \\
\text { Self- } \\
\text { Cita- } \\
\text { tion }\end{array}$ & $\begin{array}{l}\text { Ta- } \\
\text { bles, } \\
\text { Cha- } \\
\text { rts, } \\
\text { Fi- } \\
\text { gures }\end{array}$ & $\begin{array}{l}\text { Ave- } \\
\text { rage } \\
\text { no. } \\
\text { of } \\
\mathrm{Pa}- \\
\text { ges }\end{array}$ \\
\hline RevA.10 & Yes & 2002 & $* *$ & $* *$ & $* * *$ & $*$ & $\begin{array}{l}\text { A.3+O } \\
.48\end{array}$ & 48 & Fig.1 & 19 \\
\hline RevA.11 & Yes & 2002 & $* *$ & $* *$ & $* * *$ & $*$ & $\begin{array}{l}\text { A.1+1 } \\
95\end{array}$ & 22 & $\begin{array}{l}\text { f.1+t. } \\
1\end{array}$ & 22 \\
\hline RevA.12 & Yes & 2002 & $* *$ & $* *$ & $* * *$ & $*$ & $\begin{array}{l}\text { A.5+ } \\
\text { W. } 7+9 \\
0\end{array}$ & 5 & f.1 & 20 \\
\hline RevA.13 & NO & 2003 & $* *$ & $* *$ & $* * *$ & $* * *$ & $\begin{array}{l}\text { A. } 6+4 \\
1\end{array}$ & 3 & - & 18 \\
\hline RevA.14 & Yes & 2003 & $* *$ & $* *$ & $* * *$ & * & 102 & - & - & 21 \\
\hline RevA.15 & Yes & 2003 & $* *$ & $* *$ & $* * *$ & NO & 40 & 7 & - & 13 \\
\hline RevA.16 & NO & 2003 & $* *$ & $* *$ & $* * *$ & $*$ & $\begin{array}{l}\text { A.5+1 } \\
09\end{array}$ & 2 & - & 20 \\
\hline RevA.17 & Yes & 2004 & $* *$ & $* *$ & $* * *$ & $* * *$ & $\begin{array}{l}\text { A. } 7+7 \\
1\end{array}$ & 3 & f.1 & 22 \\
\hline RevA.18 & NO & 2004 & $* *$ & NO & $* * *$ & $* * *$ & $\begin{array}{l}\text { A.4+1 } \\
01\end{array}$ & 5 & - & 17 \\
\hline RevA.19 & Yes & 2004 & $* *$ & $* *$ & $* * *$ & $*$ & $\begin{array}{l}\text { A.8+1 } \\
16\end{array}$ & 4 & - & 25 \\
\hline RevA.20 & NO & 2004 & $* *$ & $* *$ & $* * *$ & $*$ & $\begin{array}{l}\text { A.15+ } \\
338\end{array}$ & 5 & - & 36 \\
\hline RevA.21 & Yes & 2005 & $* *$ & $* *$ & $* * *$ & $*$ & $\begin{array}{l}\text { A.5+1 } \\
27\end{array}$ & 10 & - & 22 \\
\hline RevA.22 & NO & 2005 & $* *$ & $* *$ & $* * *$ & $*$ & 60 & 1 & - & 19 \\
\hline RevA.23 & Yes & 2005 & $* *$ & $* *$ & $* * *$ & NO & $\begin{array}{l}\text { A. } 6+1 \\
61\end{array}$ & 23 & f.1 & 27 \\
\hline RevA.24 & NO & 2005 & $* *$ & $*^{*} \mathrm{E}$ & $* * *$ & * & $\begin{array}{l}\text { A. } 5+3 \\
3\end{array}$ & - & - & 20 \\
\hline RevA.25 & NO & 2006 & $* *$ & $*_{\mathrm{E}}$ & $* * *$ & NO & $\begin{array}{l}\text { A.5+1 } \\
22\end{array}$ & 5 & f.1 & 31 \\
\hline RevA.26 & Yes & 2006 & $* *$ & $* *$ & $* * *$ & $* * *$ & $\begin{array}{l}\text { A. } 4+9 \\
5\end{array}$ & 10 & - & 21 \\
\hline RevA.27 & Yes & 2006 & $* *$ & $* *$ & $* * *$ & * & $\begin{array}{l}\text { A. } 4+5 \\
7\end{array}$ & 1 & f.1 & 14 \\
\hline RevA.28 & NO & 2006 & $* *$ & NO & $* * *$ & $*$ & $\begin{array}{l}\text { A. } 5+8 \\
9\end{array}$ & 9 & - & 26 \\
\hline
\end{tabular}


Table 4 (continued).

\begin{tabular}{|c|c|c|c|c|c|c|c|c|c|c|}
\hline $\begin{array}{l}\text { Data } \\
\text { No. }\end{array}$ & $\begin{array}{l}\text { Sin- } \\
\text { gled } \\
\text { Au- } \\
\text { thor }\end{array}$ & $\begin{array}{l}\text { Date } \\
\text { of } \\
\text { Pub. }\end{array}$ & Abs. & $\begin{array}{l}\text { In- } \\
\text { tro }\end{array}$ & $\begin{array}{l}\text { The } \\
\text { Main } \\
\text { Body }\end{array}$ & Conc & $\begin{array}{l}\text { Avera } \\
\text {-ge } \\
\text { no. } \\
\text { Refe- } \\
\text { rence } \\
s\end{array}$ & $\begin{array}{l}\text { Aver- } \\
\text { age } \\
\text { Self- } \\
\text { Cita- } \\
\text { tion }\end{array}$ & $\begin{array}{l}\text { Ta- } \\
\text { bles, } \\
\text { Cha- } \\
\text { rts, } \\
\text { Fi- } \\
\text { gures }\end{array}$ & $\begin{array}{l}\text { Ave } \\
- \\
\text { rage } \\
\text { no. } \\
\text { of } \\
\text { Pa- } \\
\text { ges }\end{array}$ \\
\hline RevA.29 & NO & 2007 & $* *$ & $* *$ & $* * *$ & $*$ & $\begin{array}{l}\text { A.7+7 } \\
0\end{array}$ & 2 & $\begin{array}{l}\text { f.1+t. } \\
3\end{array}$ & 22 \\
\hline RevA.30 & NO & 2007 & $* *$ & $* *$ & $* * *$ & $*$ & $\begin{array}{l}\text { A. } 6+ \\
\text { W. } 5+2 \\
2\end{array}$ & 4 & $\begin{array}{l}f .1+p \\
.14^{*}\end{array}$ & 20 \\
\hline RevA.31 & Yes & 2007 & $* *$ & $* *$ & $* * *$ & $* * *$ & $\begin{array}{l}\text { A. } 3+1 \\
50\end{array}$ & 7 & - & 30 \\
\hline RevA.32 & Yes & 2007 & $* *$ & $* *$ & $* * *$ & $*$ & $\begin{array}{l}\text { A.7+9 } \\
5\end{array}$ & 6 & - & 21 \\
\hline
\end{tabular}

Note. ${ }^{*}=$ the conventional heading shows the section; ${ }^{*} \mathrm{E}=$ Embedded with next section; ${ }^{* *}=$ No conventional section heading, but the content represents the section; $* * *=$ Content section heading; A.: Annotated References; W.: Websites; f.: Figure; t.: Table; p.: Picture; o.: Other References; Abs.: Abstract; Intro.: Introduction; Conc.: Conclusion

Based on the specific details presented in Table 4, the second column indicates whether the review article has one single author or more than one. The third column shows us the date of publication of review articles which varied from 2000 to 2007. The fourth, fifth, sixth and seventh columns tell us if the sections are present or not (this sign "*" shows the presence of conventional heading, "**" this sign shows there is no conventional section heading, and this "***" shows that there is a content section heading). For example, the fourth column shows whether the abstract section is present for the first review article of the corpus (RevA.1). The textual structure of this review article is in Table 5. This table indicates that the abstract section does not exist, the body section contains content headings and the conclusion section is not also present and there is no conventional section heading for this section.

Table 5

Overall textual structure for review article 1

\begin{tabular}{llc}
\multicolumn{1}{c}{ Functional } & \multicolumn{1}{c}{ Section headings in Review Article } & $\begin{array}{c}\text { Sub-headings in } \\
\text { Review Article }\end{array}$ \\
\hline Abstract & No Abstract & ----- \\
Introduction & Introduction \\
The Body section & $\begin{array}{l}\text { Linguistics and Language Teaching } \\
\text { Corpus Linguistics, Authentic Language, }\end{array}$ \\
& $\begin{array}{l}\text { and Task-based Instruction } \\
\text { Linguistics, Language Teaching, and }\end{array}$ \\
& Applied Linguistics
\end{tabular}


In addition, Tables 4 and 5 reveal that there is no section heading at all for the Abstract section. The authors may use varied section headings for signalling the analytical sections of review articles, and sometimes they represent content section headings like theme-bound units in the Body section. The content section heading is signaled with unconventional section heading or theme-based section heading but it represents the functions of the analytical section. For instance, there are no conventional section headings for the Body sections in the corpus of this study, but we have identified these sections with "content section headings" or "theme-based section headings". The characteristic features and organisational structure of review articles in applied linguistics were further investigated by consulting our specialist informants. Some of the feedback and views received from the informants have been included in the following section. The questions (' $i$ ' and 'ii') and the informants' feedback taken from the questionnaire:

Based on the findings, review articles do not have the standard headings like many research articles and they do not follow the IMRD (Introduction, Method, Result, and Discussion) model.

i. Is there a particular order in which you write a review article?

1. "The headings are based on content, but the very first section is an introduction, on main themes, and then headings should go from more general to specific. The final section tends to sum up main trends and what needs to be researched...". (Informant ' 5 ')

2. "a) Summary of previous reviews, if any,

b) Delineating the Parameters of the review, components of the research area,

c) Reviewing and critiquing research in each component,

d) Concluding, summarising, looking forward,

e) Bibliography" (Informant ' 6 ')

3. "Vignette, definition, literature review, critique, and conclusions" (Informant '7')

4. "No, it entirely depends on the themes that emerge when I do the preparatory work" (Informant ' 8 ')

5. "Other than an introduction, a section on future directions, and final conclusions, the articles do not follow a uniform pattern for me. The topic itself tends to suggest section headings...". (Informant ' 9 ')

ii. There are no Section Headings like 'Abstract' or 'Introduction' in the review text. Why? Is it because of the editorial policy of ARAL? Or it is the result of choices made by the respected writer?

1. "I assume that it is a decision or policy of ARAL". (Informant ' 9 ')

The feedback and views received from the informants supported the findings of the present research. The characteristic features and organisational structure of review articles in applied linguistics which were analysed and described in this study were confirmed by consulting our specialist informants. In most of review articles in the corpus of this study, for example, we could not find section heading for the Introduction section, except three review articles those published in 
2000 and before 2000 (i.e. 'Volume No. 20' and before this volume). Thus, according to our specialist informants' views, this is a decision or policy taken by ARAL. One of the informants even believes that the overall organisational structure of review articles can be as the following: Vignette, definition, literature review, critique, and conclusions (Informant ' 7 '). Another informant, yet, believes that review articles do not follow a uniform pattern for him. He has further added that the topic itself tends to suggest section headings. As it has been discussed above, the content section heading is signalled with unconventional heading but it represents the functions of this section. These sections might be mixed and embedded with other sections in review articles. Therefore, it is important to find out that a section is embedded with other section in some review articles of this research (like the Introduction section can be embedded with the first sub-heading thematic unit of the Body section). Take for example in the corpus (RevA.6 and RevA.25), there is no conventional signal or heading for the Introduction sections and they are embedded within the first subheadings of the Body sections, because the main purpose of these chapters is included in the first theme-bound unit of the Body sections.

Table 6

Overall textual structure for review article 6

\begin{tabular}{|c|c|c|}
\hline $\begin{array}{l}\text { Functional } \\
\text { sections }\end{array}$ & Section headings in the review text & $\begin{array}{l}\text { Sub-headings in the } \\
\text { review text }\end{array}$ \\
\hline Abstract & $\begin{array}{l}\text { No section heading, but the content } \\
\text { represents the section }\end{array}$ & \\
\hline Introduction & $\begin{array}{l}\text { No section heading, but it was } \\
\text { embedded within the first sub- } \\
\text { heading of the Body }\end{array}$ & \\
\hline \multirow[t]{8}{*}{ The Body section } & The Neurobiological Circuitry & - The Amygdala \\
\hline & & $\begin{array}{l}\text {-The Orbitofrontal } \\
\text { Cortex } \\
\text { - The Body Proper }\end{array}$ \\
\hline & From Stimulus Appraisal to & \\
\hline & Motivation & \\
\hline & From Appraisal to Behavior: & \\
\hline & Translating Motivation into Action & \\
\hline & Decision-Making in Language & \\
\hline & Pragmatics & \\
\hline Conclusion & Conclusion & \\
\hline
\end{tabular}

As discussed in the methodology section, this was considered as one of the challenges of this research. In Table 6, we can find different sections are embedded and the findings highlighted specifically for each review article in the corpus of this research. 


\section{The Abstract Section of Review Articles}

According to Table 3, almost more than $85 \%$ of review articles (28 out of 32 ) contained the Abstract section except four review articles in the corpus of this research. In the Abstract section the writers tried to give a preview of the review, and it was typed in a smaller font size. This section in review articles attracts our attention through its being outstanding and different from the other sections. In the Abstract sections of the corpus there is no conventional section heading "Abstract", however one can realise that this section not only has summarised the whole ideas and points included in review article but it can also tell the audience the kind of text types the review article contains. Besides, the first four reviews in the data do not contain this section at all because it seems that those review articles which were published in 2000 and before 2000 followed a different style and format based on the editorial policy of the ARAL journal on the writing of review articles. Therefore, they do not contain the Abstract section. Instead, the review articles published from 2001 onwards contain the Abstract section without its conventional section heading. There is a possibility of change in the format and style of review articles over these years. There are mostly often four moves for the Abstract section in review articles in applied linguistics namely "situating the review", "presenting an issue", "presenting the review", and "discussing the review". This move pattern for the Abstract section of review articles in applied linguistics fits Santos' (1996) model, with two moves missing, namely, "describing methodologies" and "summarising the results". These two moves do not usually appear in review articles and it seems that Santos' model does not conform completely to the actual practice of abstracting in the review article genre in applied linguistics (see Appendix B for coding scheme of move analysis).

\section{The Introduction Section of Review Articles}

According to the analysis of the organisational structure of review articles, the Introduction section with its exact conventional section heading was found in three review articles in the corpus, and likewise this section was not present in the three review article texts of the corpus. Moreover, the Introduction section without the conventional section heading appears between the Abstract section and the Body section of review articles, was realised in 26 review articles.

As the findings of this research revealed, the conventional section heading "Introduction" was absent in the 26 review articles. However, the content and pattern of this section were there and it represented an introduction. They often to some extent followed Swales' CARS model as in the Introduction section of experimental research articles (see Appendix B for move examples provided from the corpus). The researchers read this section of the corpus carefully before identifying the rhetorical move structure for this section (i.e. as the nature of genre analysis is pattern seeking). The move types were identified based on the type of review articles in applied linguistics, namely, Move 1 (establishing the background), Move 2 (narrowing down the scope of the review), and Move 3 (presenting the review). Move 2 was identified in review articles that were evaluative, presenting/or 
raising issues of the field and showing a lack of study in the field. It should be added that Move 2 was less frequent than the other moves in the bibliographic review articles. It was noticed that there is a significant variation among the text types of the review article genre in terms of Moves and Sub-moves. In other words, the schematic structure for the Introduction sections in the three types of review articles (i.e. "critical evaluative", "bibliographic", and "mixed-mode" review articles) cannot be the same. Those review articles in applied linguistics, for example, which were descriptive and indicated comprehensive record of the developments did not contain Move 2. This move was observed more frequently in the evaluative and critical review texts than descriptive review texts. Therefore, there is a variation between the schematic structure of bibliographic review articles and the critical evaluative review articles in terms of Moves, Sub-moves and rhetorical strategies (for more details regarding the review article genre in applied linguistics and the classification system see Sorayyaei Azar \& Hashim 2014; 2017a; 2017b).

In the second phase of this research, the characteristic features and organisational structure of review articles in applied linguistics were further investigated by consulting the specialist informants in the field of applied linguistics who were the solicited authors of the review articles in ARAL journal. Some of the questions that have been posed via face-to-face interview or e-mail interview and their feedback were brought here to illustrate their ideas and viewpoints. The first question is related to the particular order of writing a review article and the second question dealt with certain aspects that have been included in writing the beginning section of review articles in applied linguistics by respected authors. The informants of the present research gave their views and feedback, and they were taken for granted in our findings. The following item and the questions (i.e. ' $i$ ') taken from the questionnaire:

i. What are the main aspects which you normally include in writing the beginning section of review article?

1) "The main themes discussed and their sequence in which they are presented..." (Informant 5)

2) "Summarising most recent reviews, if any, and asking what progress has been made since it was published. If no previous review exists, summarising research up to the timeline of the current review article" (Informant 6)

3) "I try to include a vignette which illustrates an important aspect of the topic I am reviewing". (informant 7)

4) "I would pose a question or puzzle, and indicate why it's important to find an answer and how l'll try to do that in the paper" (Informant 8)

5) "Introduce the topic and explain its contemporary relevance to the field, define key terms, identify existing "gaps", and provide an overview of the treatment to follow" (Informant 9)

Their feedback and views to our analysis and description of review articles in applied linguistics are really informative and presented a crystal-clear image of the different sections of review texts particularly for the conventional sections like the Introduction section. 


\section{The Body Section of Review Articles}

Based on the identified sections in the Body section of review articles in this research, there were content-based sections almost in all review articles (30 out of 32) except in two (RevA.20 and RevA.22). In the first one (RevA.20), the heading "Review of Research" was found following its beginning (i.e. Introduction) section. The authors tried to review and reflect on developments in the teaching of second language writing between 2000 and 2004 and they identified many potential areas for future research. While, in the second one (RevA.22) the authors tried to survey longitudinal second language acquisition research published between 2003 and 2005. They also offered a critical reflection of best longitudinal practices. More importantly, they partially followed IMRD model in this review article of the corpus and used the conventional section headings like "Methodology for the Present Review", several sub-arguments and discussions that represented "methodological discussion" section, "Future Directions" and "Concluding Remarks". In the entire of the corpus, each section heading in the Body section could be identified and divided by a different font or bold-typed words/ or phrases. In other words, it can be shown that each section heading in the Body section talks about a specific theme. In the beginning of each theme there is usually a thematic phrase or word which is typed in bold font, and following these main thematic topics there are often sub-themes which are typed as the underlined to separate the sub-units from the usual paragraphs of review article. The number of these theme-bound units in the Body section of review articles is not fixed and predictable. Due to highly recursive, complex and length of thematic units in the Body section it was decided to focus on argumentation across the thematic units. The researchers attempted to analyse and identify how argumentative patterns were formulated and shaped in these thematic units of the Body section.

As a matter of fact, the main attempt for analysing thematic units was to investigate and identify which argumentative pattern was used in the review article genre. In other words, analysis of theme-bound units in the Body section of the review article genre need not always be prescriptive and it should not necessarily be based on CARS model. Therefore, we examined the function of each theme-bound unit according to its local purpose (i.e. the authors try to focus on the turning points or issues related to the main title of review article), then according to its communicative purpose (i.e. the global purpose of the title mentioned in that review article) and the writer's communicative intention (i.e. the authors may intrude their attitude and stance in evaluation of the developments in a research). As it has been discussed before, the scope for genre analysis of theme-bound units in the Body section was narrowed down to the analytical framework used by Hatim and Mason (1990) for argumentative discourses. We then identified which argumentative text type pattern (i.e. "through-argumentation" in which thesis cited to be evaluated and the authors' evaluation and argument go in line with other scholars' views or "counter-argumentation" in which thesis cited to be opposed and the authors make counter claim) was commonly used for the thematic units in review articles. Then, the prototypical argumentative pattern (i.e. what types of argumentative text types were used in the review texts) for the thematic units which were involved in 
argumentation was proposed for the different types of review articles in applied linguistics (see Sorayyaei Azar \& Hashim, 2017a).

\section{The Conclusion Section of Review Articles}

In this study, the Conclusion section was found in 28 review articles of the data (see Tables 3 and 4), while the Conclusion section did not occur in the four review articles of the corpus. At the same time, in one of the review articles (RevA.25) the section heading "Future directions and challenges" (i.e. it indicated challenges and issues in English as a lingua franca) was used. This section appeared in very lengthy, recursive, cyclical paragraphs. The analysis of this section (i.e. "future directions and challenges" in RevA.25) indicates that there is variation with respect to the moves and rhetorical strategies that exist within this section (i.e. some of the strategies in this section are defining the challenge, analysing the reasons, presenting the idea, indicating a need, asserting the confirmative claims about the research, raising a question, reviewing previous works, suggesting possible solutions, and highlighting the authors' view). In addition, in another review article (RevA.31) the section heading "Final Mark" is shown and used instead of using the "conclusion" heading. This section is too similar to the Conclusion section. Besides, two other review articles (RevA.17 and RevA.13) used the section heading "Directions" to show new directions/or trends in the related research and also give suggestions for further research to the readers, and also in the data (RevA.3) the heading "Final Consideration" is identified. In two of the other review articles (RevA.16 and RevA.28) the "Implication" section is identified. Besides, the "pedagogical implication" section appears separately before the Conclusion section in some review articles (e.g. RevA.31 and RevA.32).

Based on the findings of this research, there are three prevalent moves for the Conclusion section in review articles in applied linguistics namely "summarising the review", "evaluating the review", and "giving suggestions" (see Appendix B). This move pattern for the Conclusion section of review articles in applied linguistics fits Yang and Allison's (2003) model. These three moves usually appear in review articles and it seems that Yang and Allison's model conforms completely to the actual practice of concluding in the review article genre in applied linguistics. The analysis of the rhetorical move structure for the Conclusion section will be presented and discussed in our forthcoming research paper.

\section{References of Review Articles}

There are usually two kinds of references given in review articles of the corpus of this research, namely "Annotated References" and "Unannotated References". The former is giving and introducing those kinds of references which their purposes and content are described in detail, but the latter is introducing the cited references in the review in a usual way. The section heading "Unannotated References" was replaced by the section heading "Other References" from 2002 onward. The heading "Unannotated References" was displayed in the years 2000 to 2001 of the data (see Table 4 for more details of the average number of references in each data). It is 
essential to note that the style of citation and giving references is changed during the time in review articles (Noguchi, 2009, as cited in Hyland \& Diani, 2009).

\section{Self-citation in Review Articles}

According to this study, there are signs of self-citation by the writers in almost all of review articles (30 out of 32 review articles). The most highly self-cited review articles are RevA.10 (48 times), RevA.9 (38 times) and RevA.23 (23 times) from the corpus respectively. The average mean of self-citation was 8.4 for each review article in the corpus.

\section{Page Numbers of Review Articles}

The average number of pages is 19 for review articles in this research (see Table 2).

\section{Figures/Tables/ Notes in Review Articles}

Among review articles in the corpus of this research, there were nine review articles which contained figures or tables (see Table 3). In RevA.30, 14 pictures, 14 transcripts and two texts and fragments were found. At the same time, the "Notes" sections were found in 22 review articles in the corpus, and also there were the "Appendix" sections in the two review articles of the data (RevA.10 and RevA.30). There was only the "Appendix" section in RevA.10. It is found that the "Acknowledgment" section occurs in the "Notes" section in few review articles of the corpus.

As the analysis of macro-organisational structure in the corpus of this research developed, there emerged a predominant structure of review articles in applied linguistics. This macro-textual structure consists of four major sections, namely, the Abstract, Introduction/ or Beginning, Body, and Conclusion sections (see Figure 1). The move patterns and rhetorical structures for the Abstract, Introduction and Conclusion sections in review articles in applied linguistics have been presented and discussed in the forthcoming research paper (Sorayyaei Azar \& Hashim, forthcoming).

Based on Figure 1, and the structural organisation of Literature Review chapters in PhD theses highlighted by Kwan (2006), we note of the following points. The first point is that these genres, namely, the review article genre and literature review genre are to some extent closely related to each other. In other words, they are from the same "genre family" (Swales, 2004) or "genre colony" (Bhatia, 1997, 2004). According to Swales' (2004, p. 66) belief, we can further add that one family member such as the review article genre may take on several features of another member (e.g., the literature review genre). Although their main functions are different from each other, we can find some similarities not only in rhetorical structures of these two sub-genres but in their writers' textual strategies or rhetorical devices as well (Sorayyaei Azar \& Hashim, 2017b). If we compare, for instance, their structural organisations, we can find similarities. 


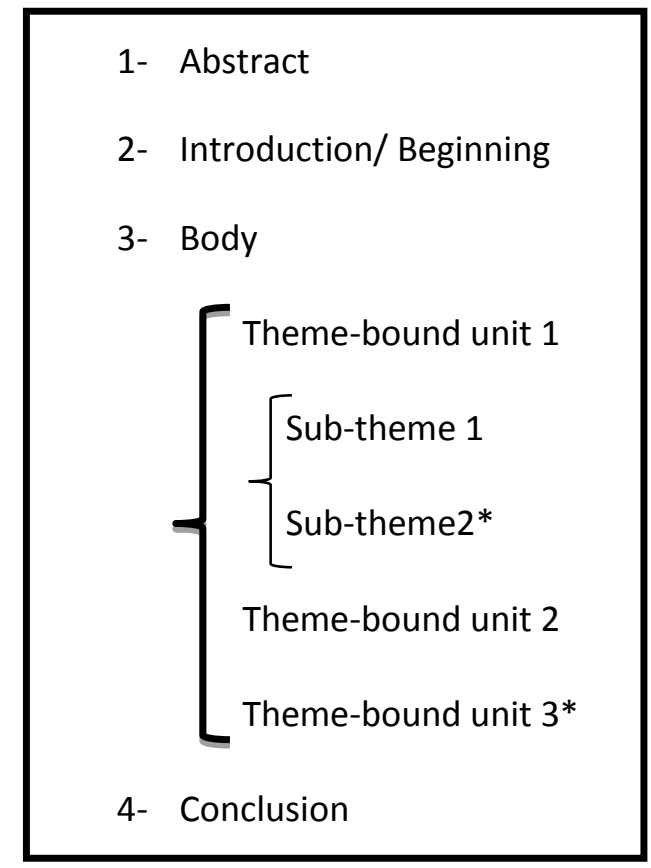

* The number of theme-bound units \& sub-theme units are not fixed.

Figure 1. Organisational structure of review articles

The second one is that these forms of reviews as sub-genres of academic review genres have become increasingly evaluative and persuasive. The persuasive and evaluative functions of academic review genres are significant features which implicitly and explicitly can be predominantly indicated and emphasised by writers. Book reviews, for example, try to make a balanced description of books not only positively but also negatively. It attempts to praise and criticise the positive and negative aspects of the product in the marketing and academic settings. And as Bhatia (2004) believes, food and restaurant reviews emphasis the positive description and evaluation of the foods. In other words, their feature can be considered promotional and the functions of these genres, such as reviews, are introducing, giving information, evaluating, convincing, and recommending products (Sorayyaei Azar \& Hashim, 2017a). Take for instance, a blurb according to Bhatia (2004) can carry at least three moves. "These moves, namely 'Establishing Credentials', 'Introducing the Product', and 'Indicating Value of the Product', are too similar to an advertisement" (Bhatia, 2004, p. 93). It appears that the blurbs, which can be considered as one of the academic review genres, reviews the book from one angle and advertise from another angle. In fact, it can be contended that this multifunctionality of academic review genres is very remarkable and it can be taken into consideration. The review article genre also can represent multi-functions. The multifunctionality of the review article genre depends on its type and level of criticality. As it has been discussed somewhere else (Sorayyaei Azar \& Hashim, 2014), we can classify the review article genre based on its text types and criticality and represent the review text types on the continuum. According to Sorayyaei Azar and Hashim (2014, p. 81): 
This continuum can demonstrate the functionality variation among review articles whether they function as evaluative review or descriptive and indicative review. In addition, it shows variety of the text types as well as the intended audiences of the reviews.

Thus, the review article genre in applied linguistics can represent various functionality and that is how interestingly there is variation among one single genre in the same discipline, that is to say the review article genre. Sorayyaei Azar and Hashim (2014, p. 81) further add:

This vertical continual spectrum demonstrates the degree of criticality among the text types of the review articles in applied linguistics...this continuum is ranging from the bibliographic review through the mixed mode to the critical evaluative review. These reviews, in fact, differ from each other in the kind. Actually, the less evaluative and more narrative form is the bibliographic review. From this one if we go up the continuum, we could proceed through a review following a mixed-mode design (i.e. narrative and evaluative texts mixed) and encompassing both approaches. Finally, we could reach a critical evaluative review. This type of review seeks to question and discusses the question, analyses and evaluates the recent developments, reviews and compares the debates, and offers possible solutions and suggests new directions. This type of review article has offered comprehensive, timely collections of critical evaluative reviews written by solicited expert members of the discourse community.

In short, there are similarities and divergences across such sub-genres, based on our analysis of a set of linguistic devices and features targeting review articles in applied linguistics. The findings indicate that review articles in applied linguistics may differ from each other in the kind and their functions. They often occupy their own ideal areas in the classification continuum expressing on the one hand their intended audiences and variation in authorship and, on the other hand, variation in criticality of the text types based on their communicative purposes. In other words, critical evaluative intensity seems to depend on the rhetorical functions, characteristics, and purposes of the review article genre.

\section{Conclusion}

This study analysed the macro-organisational structure of review articles in applied linguistics. From the results, it is concluded that the CARS model was sometimes observed in the review article genre. In addition, the findings revealed that there is a variation between the research article genre and review article genre in terms of macro-organisational and micro-organisational structures (i.e. Moves, Sub-moves, and rhetorical strategies). It should be added that almost more than $85 \%$ of review articles contained the Abstract section, the Introduction section without the conventional section heading was realised in 26 review articles, there were themebound units in the Body section almost in all review articles (30 out of 32) except in two, and the Conclusion section was found in 28 review articles of the data. Based on the findings of this research, there are four prevalent moves for the Abstract 
section, three major moves for the Introduction section, and three main moves for the Conclusion section in review articles in applied linguistics. The Body section was highly recursive and complex so we decided to focus on argumentation across the thematic units. The researchers attempted to analyse and identify how argumentative patterns were formulated and shaped in these thematic units of the Body section. Moreover, the characteristic features and organisational structure of review articles in applied linguistics were further investigated by consulting the specialist informants in the field of applied linguistics who were the solicited authors of the review articles in ARAL journal.

It is hoped that a closer understanding of the macro and microorganisational structures and rhetorical strategies of review articles helps uncover elements of the value system for EFL graduate students and junior researchers. These elements of the value system not only emphasise disciplinary discourse but also provide EFL graduate students and junior researchers with the ability to make use of scholarly review articles and primary literature during their research writing. The lecturers are also advised to teach the macro-textual structures and rhetorical strategies in the review article genre in their English for Academic Purposes (EAP) classes. This will raise the awareness of our students of the characteristic features of review articles so that they know how to monitor the review article genre and how to write academic reviews critically in their research journey. The generic features for review articles in applied linguistics can help both EFL postgraduates and junior researchers to review the developments with their critical and evaluative eyes and write their academic reviews in a more permissible style.

\section{Notes}

${ }^{1}$ This study was a part of PhD Thesis (at the Faculty of Languages \& Linguistics, University of Malaya, Malaysia) investigating the review article genre in applied linguistics (2017).

\section{Acknowledgments}

First, we express our profound gratitude to the specialist informants for their invaluable hints and comments, which really guided us to the goal of this research. The authors are also very grateful to the editorial team of Issues in Language Studies (ILS) for giving us helpful comments.

\section{References}

Adams, S. (1961). The review literature of medicine. Bibliography of medical reviews, 6.

Bhatia, V. K. (1997). Genre-mixing in academic introductions. English for Specific Purposes, 16, 181-195. 
Bhatia, V. K. (2004). Worlds of written discourse: A genre-based view. New York: Continuum.

Garfield, E. (1987). Reviewing review literature, Part I. definitions and uses of reviews'. Essays of an Information Scientist, 10, 113-116.

Groom, N. (2009). Attribution and averral revisited: Three perspectives on manifest intertextuality in academic writing. In P. Thompson (Ed.), Patterns and perspectives: Insights into EAP writing practice (pp. 14-25). Reading: CALS, the University of Reading.

Hatim, B., \& Mason, I. (1990). Discourse and the translator. London: Longman.

Hyland, K. (2000). Disciplinary discourses: Social interactions in academic writing. London: Longman.

Hyland, K. (2007). Applying a gloss: Exemplifying and reformulating in academic discourse. Applied Linguistics, 28(2), 266-285.

Hyland, K., \& Diani, G. (2009). Academic evaluation: Review genres in University settings. Hampshire: Palgrave Macmillan.

Kuhi, D., \& Behnam, B. (2010). Generic variation and metadiscourse use in the writing of applied linguistics: A comparative study and preliminary. Written Communication, 28(1), 97-141.

Kuhi, D., Yavari, M., \& Sorayyaei Azar, A. (2012). Metadiscourse in applied linguistics research articles: A cross-sectional survey. Mediterranean Journal of Social Sciences, 3(11), 405-411.

Kronick, D. A. (1962). History of scientific periodicals (1665-1790). Metuchen, N.J.: Scarecrow Press.

Kwan, K. (2006). The Schematic Structure of Literature Reviews in Doctoral Theses of Applied Linguistics. English for Specific Purposes, 25, 30-55.

Moreno, A. I., \& Suarez, L. (2008). A study of critical attitude across English and Spanish academic book reviews. Journal of English for Academic Purposes, 7(1), 15-26.

Motta-Roth, D. (1995). Same genre, different discipline: A genre-based study of book reviews in academe. The ESPecialist, 17(2), 99-131.

Myers, G. (1991). Stories and styles in two molecular biology review articles. In C. Bazerman, \& J. Pardis (Eds.), Textual dynamics of the professions. Madison: University of Wisconsin Press.

Noguchi, J. T. (2001). The science review article: An opportune genre in the construction of science (Unpublished PhD dissertation). The University of Birmingham, UK.

Noguchi, J. T. (2006). The science review article: An opportune genre in the construction of Science. Bern: Peter Lang.

Price, D. J. D. (1965). Networks of scientific papers. Science, 149, 510-515.

Ridley, D. (2008). The literature review: A step by step guide for students. London: Sage.

Sorayyaei Azar, A. (2012). The self-promotion of academic textbooks in the Preface section:A genre analysis. Atlantis, revista de la Asociación Española de Estudios Anglo Norteamericanos, 34(2), 147-165. 
Sorayyaei Azar, A., \& Hashim, A. (2014). Towards an analysis of review article in Applied Linguistics: Its classes, purposes and characteristics. $E L T, 7(10), 76-$ 88.

Sorayyaei Azar, A., \& Hashim, A. (2017a). A genre-based analysis of thematic units in review articles in applied linguistics. ESP World, Forthcoming.

Sorayyaei Azar, A., \& Hashim, A. (2017b). On evaluative markers, a rhetorical strategy in writing academic review genres: with special attention to the review article genre in applied linguistics, Forthcoming.

Swales, J. (1990). Genre analysis: English in academic and research settings. Cambridge: Cambridge University Press.

Swales, J. (2004). Research genres: Exploration and applications. Cambridge: Cambridge University Press.

Thompson, P. (2009). Literature reviews in Applied PhD Theses: Evidence and problems. In K. Hyland, \& G. Diani (Eds.), Academic evaluation: Review genres in University settings. Bern: Peter Lang.

Virgo, J. A. (1971). The review article: Its characteristics and problems. The Library Quarterly, 41(4), 275-291.

Woodward, A. (1974). Review literature: Characteristics, sources and output in 1972. AslibProc., 26, 367-376. 


\section{Appendix A}

The list of review articles used in the corpus

RevA.1: Widdowson, H.G. (2000). Object language and the language subject: on the mediating role of applied linguistics. Annual Review of Applied Linguistics, 20: 21-33.

RevA.2: Crandall, J. (2000). Language teacher education. Annual Review of Applied Linguistics, 20: 34-55.

RevA.3: Swales, J., M. (2000). Language for Specific Purposes. Annual Review of Applied Linguistics, 20: 59-76.

RevA.4: Daoud, M. (2000). LSP in North Africa: Status, Problems and Challenges. Annual Review of Applied Linguistics, 20: 77-96.

RevA.5: Segalowitz, N. (2001). On the Evolving Connections Between Psychology and Linguistics. Annual Review of Applied Linguistics, 21: 3-22.

RevA.6: Schumann, J. H. (2001). Appraisal Psychology, Neurobiology, and Language. Annual Review of Applied Linguistics, 21: 23-42.

RevA.7: Dornyei, Z. (2001). New Themes and Approaches in Second Language Motivation Research. Annual Review of Applied Linguistics, 21: 43-59.

RevA.8: Hansen, L. (2001). Language Attrition: The Fate of the Start. Annual Review of Applied Linguistics, 21: 60-73.

RevA.9: Schegloff, E. A., et al. (2002). Conversation Analysis and Applied Linguistics. Annual Review of Applied Linguistics, 22: 3-31.

RevA.10: Lazaratan, A. (2002). Quantitative and Qualitative Approaches to Discourse Analysis. Annual Review of Applied Linguistics, 22: 32-51.

RevA.11: Martin, J. R. (2002). Meaning Beyond the Clause: SFL Perspectives. Annual Review of Applied Linguistics, 22: 52-74.

RevA.12: Conrad, S. (2002). Corpus Linguistic Approaches for Discourse Analysis. Annual Review of Applied Linguistics, 22: 75-95.

RevA.13: Kymlicka, W., and Patten, A. (2003). Language Rights and Political Theory. Annual Review of Applied Linguistics, 23: 3-21.

RevA.14: Garcia, M. (2003). Recent Research on Language Maintenance. Annual Review of Applied Linguistics, 23: 22-43.

RevA.15: Hinton, L. (2003). Language Revitalisation. Annual Review of Applied Linguistics, 23: 4457.

RevA.16: Valdes, G., and Angelelli, C. (2003). Interpreters, Interpreting, and the Study of Bilingualism. Annual Review of Applied Linguistics, 23: 58-78.

RevA.17: Vandergrift, L. (2004). Listening to Learn or Learning to Listen. Annual Review of Applied Linguistics, 24: 3-25.

RevA.18: McCarthy, M., and O'keeffe, A. (2004). Research in the Teaching of Speaking. Annual Review of Applied Linguistics, 24: 26-43.

RevA.19: Grabe, W. (2004). Research on Teaching Reading. Annual Review of Applied Linguistics, 24: 44-69.

RevA.20: Silva, T., and Brice, C. (2004). Research in Teaching Writing. Annual Review of Applied Linguistics, 24: 70-106.

RevA.21: Odlin, T. (2005). Cross-linguistic Influence and Conceptual Transfer: what are the Concepts? Annual Review of Applied Linguistics, 25: 3-25. 


\section{Appendix A (continued).}

RevA.22: Ortega, L., and Iberri-Shea, G. (2005). Longitudinal Research in Second Language Acquisition: Recent Trends and Future Directions. Annual Review of Applied Linguistics, 25: 26-45.

RevA.23: Robinson, P. (2005). Aptitude and Second Language Acquisition. Annual Review of Applied Linguistics, 25: 46-73.

RevA.24: Tarone, E., and Bigelow, M. (2005). Impact of Literacy on Oral Language Processing: Implications for Second Language Acquisition Research. Annual Review of Applied Linguistics, 25: 77-97.

RevA.25: Seidlhofer, B., et al. (2006). English as a Lingua Franca in Europe: Challenges for Applied Linguistics. Annual Review of Applied Linguistics, 26: 3-34.

RevA.26: Canagarajah, A. S. (2006). Negotiating the Local in English as a Lingua Franca. Annual Review of Applied Linguistics, 26: 197-218.

RevA.27: Pickering, L. (2006). Current Research on Intelligibility in English as a Lingua Franca. Annual Review of Applied Linguistics, 26: 219-233.

RevA.28: Nikolov, M., and Mihaljevic Djigunovic, J. (2006). Recent Research on Age, Second Language Acquisition, and Early Foreign Language Learning. Annual Review of Applied Linguistics, 26: 234-260.

RevA.29: Warchauer, M., and Grimes, D. (2007). Audience, Authorship, and Artifact: The emergent Semiotics of Web.2. Annual Review of Applied Linguistics, 27: 1-23.

RevA.30: Markee, N., and Stansell, J. (2007). Using Electronic Publishing as a Resource for Increasing Empirical and Interpretive Accountability in Conversation Analysis. Annual Review of Applied Linguistics, 27: 24-44.

RevA.31: Belz, J. A. (2007). The Role of Computer Mediation in the Instruction and Development of L2 Pragmatic Competence. Annual Review of Applied Linguistics, 27: 45-75.

RevA.32: Blake, R. J. (2007). New Trends in Using Technology in the Language Curriculum. Annual Review of Applied Linguistics, 27: 76-97. 


\section{Appendix B}

Examples of moves (from the four analytical sections of review articles) provided from the corpus to illustrate the move structure

Move1: Situating the Review

\section{Abstract}

By Strategy1: Providing the Background on the Previous Research

1) ...language revitalisation, a movement that dates approximately from the 1990s and builds on prior work on language maintenance (see Fishman, 1991; 2001) and language death (Dorian, 1981; 1989). (RevA.15, Abstract, Mixed-mode Review Article)

Strategy2: Defining and Elaborating an Idea/ Theme

2) Over four decades ago the so-called Chomskyan revolution appeared to lay the foundation for a promising new partnership between linguistics and psychology. (RevA.5, Abstract, Critical Evaluative Review Article)

Move2: Presenting an Issue

By Strategy1A: Raising a Question

1) Yet, many of these discussions conceive of Europe as a group of nation states where English is either a first or a foreign language. This chapter seeks to question this well-established distinction... (RevA.25, Abstract, Critical Evaluative Review Article)

Strategy1B: Indicating a Gap/ Lack of Study

2) Unfortunately, all studies focus only on English discourse, which suggests that analyses of discourse in other languages are clearly needed; moreover, it was extremely difficult to find published discourse analytic studies... (RevA.10, Abstract, Mixed-mode Review Article)

\section{Strategy 1C: Presenting an Issue}

3) Many have now concluded, however, that the hopes originally expressed for this partnership were not realised. (RevA.5, Abstract, Critical Evaluative Review Article)

Move3: Presenting the Review

By Strategy1: Stating the Writer's Main Purpose/ or View

1) This chapter is about what went wrong and where we might go from here. (RevA.5, Abstract, Critical Evaluative Review Article)

Strategy2: Outlining the Structure of the Review

2) First, we summarise..., then we review recent findings...Finally, we explore areas for further research. (RevA.28, Abstract, Critical Evaluative Review Article) 


\section{Appendix B (continued).}

\section{Move4: Discussing the Review}

By Strategy1: Giving suggestions or interpreting the discussions

1) Readers of CA research may now expect to have access to primary as well as secondary data... We also suggest that readers will be able to engage in ... (RevA.30, Abstract, Critical Evaluative Review Article)

Strategy2: Giving recommendations, implications or applications of the study

2) Possible directions for further research are also considered. (RevA.27, Abstract, Bibliographic Review Article)

\section{Move1: Establishing the Background}

\section{Introduction}

By Strategy1: Claiming Centrality

1) As Linguistics has extended its scope over the past thirty years from an exclusive concern with knowledge of the abstract code... (RevA.1, Introduction, Critical Evaluative Review Article)

Strategy2: Reviewing Previous Research

2) Since the start, the expansion of interest in language attrition can be seen in a bevy of books (Hansen, 1999; Kenny, 1996; ...) and dissertations (Ammerlaan, 1996; Bolonyai, 1999; ...), and a succession of symposia on the subject at applied linguistics conferences; see Hansen (2000) for details. (RevA.8, Introduction, Bibliographic Review Article)

\section{Move2: Narrowing Down the Scope of the Review}

\section{By Strategy1A: Identifying an Idea, a Challenge, or an Issue}

1) Nevertheless, relatively speaking, psychological research on language today is far less driven by recent advances in theoretical linguistics makes little reference to current developments in psychology...the sad truth is that many psychologists interested in language have not kept up with recent developments in linguistics... (RevA.5, Introduction, Critical Evaluative Review Article)

\section{Strategy1B: Showing a Need or a Lack of Study}

2) ...this overview will focus on students who need to develop academic reading abilities in school settings. Separate reviews would be required for adult literacy... (RevA.19, Introduction, Mixed-mode Review Article)

\section{Strategy1C: Raising a Question}

3) SLA researchers who would like to pursue longitudinal research programs can find little guidance about questions such as: What problems about the development of $L 2$ competencies have SLA researchers investigated longitudinally?... (RevA.22, Mixed-mode Review Article) 


\section{Appendix B (continued).}

Move3: Presenting the Review

By Strategy1: Stating the Writer's Purpose or Presenting the Review

1) In this chapter, I provide an overview of... (RevA.12, Introduction, Bibliographic Review Article)

Strategy2: Presenting the Essence and Value of the Review

2) These are, then, the issues we intend to address in this contribution. (RevA.25, Introduction, Critical Evaluative Review Article)

Strategy3: Outlining the Structure of the Present Review

3) This chapter begins with a definition of the terms...The following section reviews current research in ELF...the final part of the chapter describes... (RevA.27, Introduction, Bibliographic Review Article)

\section{Theme-bound Unit}

Move1: Establishing the Background

By Strategy A: Claiming Centrality

1) The Chomskyan revolution in linguistics of the late 1950s...stimulated a profound change...making possible a new kind of collaboration with linguists... (RevA.5, Theme-bound unit, M1SA, p.4)

Strategy B: Elaborating and Introducing the Context/ or Showing Significance

2) The attitudes towards ELF and the theoretical positions related to it depend a lot on different descriptions of the model. With the realisation of the new role of ELF, we have also moved beyond earlier models of global English. (RevA.26, Theme-bound unit 26, M1SB, p.198)

Strategy C: Announcing the Other Writer's Claim

3) In this view, the content of the language subject is necessarily dependent on linguistic description... The something that the teacher is teaching, the language subject, is here equated with the linguist's object of study, the object language. (RevA.1, Theme-bound unit1, M1SC, p.22)

Strategy D: Reviewing Previous Works

4) Subsequent work has examined talk in a variety of institutional or functionally specialised settings, such as legal settings (e.g., Atkinson \& Drew, 1979; Drew, 199;...), broadcast media (e.g., Clayman, 1992; Clayman \& Heritage, in press;...),..., among others. (RevA.9, Themebound unit 2, M1SD, p.10)

\section{Move2: Announcing the Writer's Point of View}

By Strategy A: Announcing the review writer's counter claim

1) Unfortunately, this solution is incoherent. Although the state can avoid interfering with the language choices people make away from public institutions...there is no way to avoid taking a stand on a series of other language policy issues. (RevA.13, Theme-bound unit 3, M2SA, p.9) 
Appendix B (continued).

\section{Strategy B: Announcing Other Writers' View}

2) However, the emergence of powerful new techniques for modeling associative learning, such as connectionist networks (Bechtel \& Abrahamsen, 1991...) and latent semantic analysis (Landauer and Dumais, 1997) are challenging these beliefs. (RevA.5, Theme-bound unit 2, M2SB, p.8)

Strategy C: Suggesting Potential Issues/or Indicating a Gap/ a Need

3) It seems to me that this assumption of dependency is mistaken... (RevA.1, Theme-bound unit 1, M2SC, p.22)

\section{Move3: Presenting Evaluation}

By Strategy A: Discussing Problems/ or Issues Encountered by Analysing Reasons

1) Yet, until this past half decade, the regaining of forgotten language had received little attention...So far, the recent studies, along with the previous scant literature on language relearning... (RevA.8, Themebound unit 4, M3SA, p.66)

Strategy B: Referring to Others' Works/ Views to Synthesise Literature

2) Dudley-Evans and St John (1998), Johns and Dudley-Evans (1991), and Robinson (1991), the defining references on ESP, do not discuss these important obstacles....Among the twelve ESP certificate programs listed in Holden (1998), only one offers a language policy course...Daoud (1999) discusses some of the obstacles to ESP growth in Tunisia in terms of the management of innovation and concludes by questioning the commitment of Tunisian educational policy makers to ESP development...These issues are occasionally addressed by international ESP guest speakers in local contexts (e.g., Grabe 1996, Swales 1993, 1994); however they are given more attention in the language policy... (RevA.4, Theme-bound unit 3, M3SB, p.82-83)

\section{Strategy C: Contrasting and Comparing Others' Views}

3) In contrast to Cohen, Ishihara, and Sykes's use of simulated conversations and elicited discourses, Braun (2005) capitalised on CM in The ELISA Project to provide learners of English with a Web-based resource for genuine English-language oral interviews...The ELISA Project is significant because... (RevA.31, Theme-bound unit 1, M3SC, p.50)

\section{Move4: Presenting the Implication of the Review}

\section{By Strategy A: Drawing a Logical Conclusion}

1) I have discussed this elsewhere (Widdowson 1989), and this is not the place to deal with it again in detail, but we need to note that this matter of relationships is a crucial one, for in a normal experience of language, all of the features Hymes mentions come into play and interact in complex ways. (RevA.1, Theme-bound unit 1, M4 Strategy A, p.23) 


\section{Appendix B (continued).}

\section{Strategy B: Restating the Issue/ Gap/ Challenge}

2) The research hitherto on multiliteracies has largely been qualitative...still in the formative and descriptive stage of observing how such text construction practices work in small settings or few subjects... (RevA.26, Theme-bound unit 2, Move 4 Strategy B, pp. 209-210)

Strategy C: Offering Possible Solutions/ a new theory/ an approach/ a model

3) Focusing on teachers--their beliefs about teaching, learning, or classroom interaction--can help balance more top-down, productoriented conceptions of language teaching, with more nuanced, bottomup, process-oriented descriptions of specific language teaching events. (RevA.2, Theme-bound unit 2, Move 4 Strategy D, p. 38)

Strategy D: Suggesting Further Research

4) However, there is a need to move beyond these qualitative case studies and analyse larger pools of writers and compare case studies to develop a typology of strategies used to negotiate the local in English writing. (RevA.26, Theme-bound unit 2, Move 4 Strategy D, pp. 209-210)

\section{Conclusion}

Move1: Summarising the Review

By Strategy A: Reviewing the Author's Purpose/ or Idea / or claim

1) We have argued in this article that, for $C A$, the advent of the digital publishing era is not an intellectual luxury_ it is a necessity. (RevA.30, Conclusion, Critical Evaluative Review Article, p.37)

\section{Strategy B: Summing up the Review}

2) The reasons discussed here include divergent approaches regarding how a theory about language should develop... (RevA.5, Conclusion, Critical Evaluative Review Article, p.16)

\section{Move2: Evaluating the Review}

By Strategy A: Showing the Significance of the Review

1) ...the tremendous interest in corpus linguistics and its great, if uncertain, potential for LSP work of all kinds. (RevA.3, Final Considerations, Critical Evaluative Review Article, p.67)

Strategy B: Showing Limitations of the Review/or Restating the Issue/ Gap/

\section{Challenges}

2) These notions are still in need of empirical definition and socio-cultural validation... with respect to teacher education, much remains to be done to ... (RevA.4, Concluding Remarks, Critical Evaluative Review Article, p.87)

Move3: Giving Suggestions

By Strategy A: Offering possible solutions

1) More software, more adaptable to discourse concerns, needs to become available to more researchers. More computer programming classes specifically for corpus linguistics need to be offered... (RevA.12, The 


\section{Appendix B (continued).}

Future for Corpus Linguistics and Discourse Analysis, Bibliographic Review Article, p.86)

\section{Strategy B: Suggesting a new theory/ a model/ a new program}

2) The success of this enterprise depends on the development of relevant software to both enhance and supplant manual analysis...l expect this technology to affect our conception of language... (RevA.11, Connections, Bibliographic Review Article, p.62)

\section{Strategy C: Recommending Further Research}

3) It is an obvious cliche to say that more research on reading instruction is needed at this point. (RevA.19, Conclusions, Mixed-mode Review Article, p.60)

Strategy D: Drawing Pedagogical Implications

4) It would be helpful to establish minimal criteria for schools, teacher education, and classroom practice to avoid the pitfalls of the past. Applied linguistic researchers willing to direct their work to any of these important pedagogical areas... (RevA.28, Conclusions and Implications for Future Research, Critical Evaluative Review Article, p.251) 